\title{
RESPONSABILIDADE CIVIL E REGULAÇÃO DE NOVAS TECNOLOGIAS: QUESTÕES ACERCA DA UTILIZAÇÃO DE INTELIGÊNCIA ARTIFICIAL NA TOMADA DE DEÇISÕES EMPRESARIAIS
}

\section{CIVIL LIABILITY AND REGULATION OF NEW \\ TECHNOLOGIES: ISSUES ABOUT THE USAGE OF ARTIFICIAL INTELLIGENCE IN BUSINESS DECISION-MAKING}

\author{
CHIARA SPADACCINI DE TEFFÉ ${ }^{1}$ \\ FILIPE MEDON ${ }^{2}$
}

\begin{abstract}
RESUMO: O presente artigo tem por objeto central a discussão acerca do regime de responsabilidade civil dos agentes na tomada de decisões baseadas na utilização de sistemas de inteligência artificial. A partir de um panorama acerca da regulação da inteligência artificial no Brasil, passa-se a uma abordagem sintética sobre as principais teorias da responsabilidade civil aplicáveis, utilizando-se como caso para análise a conduta dos agentes empresariais que, no âmbito das sociedades empresárias, delegam decisões, total ou parcialmente, para sistemas automatizados, cujo processo algorítmico nem sempre possui uma explicação clara, mas que, não raro, conduz a danos. Nesse cenário, as normas constitucionais, o dever de diligência e padrões éticos se mostram como parâmetros relevantes para a aferição da responsabilidade civil dos agentes.
\end{abstract}

Palavras-Chave: Responsabilidade civil; Novas tecnologias; Inteligência artificial; Agentes empresariais; Dever de diligência.

\footnotetext{
${ }^{1}$ Doutoranda e Mestre em Direito Civil pela Universidade do Estado do Rio de Janeiro (UERJ). Atualmente, é professora de Direito Civil e Tecnologia na faculdade de Direito do IBMEC. Leciona também em cursos do CEPED-UERJ, na Pós-graduação da PUC-Rio, na EMERJ, no Instituto New Law, no ITS Rio e na Pós-graduação em Advocacia Contratual e Responsabilidade Civil da EBRADI. Membro do conselho executivo da revista eletrônica civilistica.com. Coordenadora da Disciplina "Direito e Internet" da Pós-Graduação do Instituto New Law. Associada ao Instituto Brasileiro de Estudos em Responsabilidade Civil (IBERC). Foi professora substituta de Direito Civil na Universidade Federal do Rio de Janeiro (UFRJ). Advogada e consultora em proteção de dados. CV: http://lattes.cnpq.br/8699457488409780. Orcid: https://orcid.org/0000-0002-8280-8884 Contato: chiaradeteffe@gmail.com.

2 Doutorando e Mestre em Direito Civil pela Universidade do Estado do Rio de Janeiro (UERJ). Professor Substituto de Direito Civil na Universidade Federal do Rio de Janeiro (UFRJ) e de cursos de Pós-Graduação do Instituto New Law e CEPED-UERJ. Advogado e pesquisador. Orcid: https://orcid.org/0000-0002-4166-7077. Contato: filipemedon@hotmail.com
} 
ABstract: The main objective of this article is the discussion about the regime of civil liability of agents for the process of decision making based on the use of artificial intelligence systems. After establishing a panorama about the regulation of artificial intelligence in Brazil, the article moves to a synthetic approach to the main applicable theories of civil liability, using as a paradigmatic case for analysis the conduct of business agents that, within the scope of companies, delegate important decisions, totally or partially, to automated systems, whose algorithmic process does not always have a clear explanation, but often leads to damages. In this case, the constitutional rules, the due diligence and ethical standards are shown as relevant parameters for the assessment of the civil liability of these agents.

KeYwORDS: Civil liability; New technologies; Artificial intelligence; Business agents; Due diligence.

\section{INTRODUÇÃO: INTELIGÊNCIA ARTIFICIAL E RESPONSABILIDADE CIVIL}

Nos últimos anos, muito se tem discutido sobre as possibilidades de interação entre o ser humano e a inteligência artificial (IA), bem como acerca da regulação de novas tecnologias. Sistemas e robôs comandados por IA vêm sendo utilizados diretamente em espaços públicos e domésticos, como também em ambientes empresariais, e a tendência é que essa interação se torne cada vez mais presente e sofisticada, fazendo parte tanto do dia a dia quanto das mais variadas relações humanas. Diante disso, eventualmente, tais tecnologias terão que tomar decisões e definir caminhos, os quais, muitas vezes, esbarrarão em questões éticas ${ }^{3}$ e de responsabilidade dos agentes envolvidos. ${ }^{4}$

3 "A utilização de dados pessoais para alimentar os novos sistemas de inteligência artificial e a sua utilização para tomar decisões proporcionam uma acurácia bastante significativa para um número crescentes de aplicações. Isto abre espaço para, ao menos, dois temas centrais para os debates sobre autonomia e direitos fundamentais nos próximos anos: os efeitos que a utilização desses sistemas causarão para a pessoa e sua autonomia pessoal, bem como a necessidade de qualificar a natureza desses instrumentos e sistemas de inteligência artificial. Nesse debate, a necessidade de que sejam proporcionadas soluções que preservem os direitos fundamentais, dentro de um quadro de intenso desenvolvimento tecnológico e mesmo de questionamento de alguns institutos centrais do ordenamento jurídico, sugere a necessidade de recorrer à ética como instrumento capaz de encaminhar soluções que, eventualmente, e se for o caso, possam consolidar-se em alternativas legislativas posteriormente" (DONEDA et al., 2018, p. 03).

${ }^{4}$ Sobre esse ponto, recorda-se fala de Ginni Rometty (COLEMAN, 2019), diretora executiva da International Business Machines Corp. (IBM): "What is vital is to make anything about AI 
Questiona-se, com frequência, se seria necessário criar normas e institutos específicos para tratar de matérias relativas à inteligência artificial e robôs ou se deveriam ser aplicadas as normas já existentes para as novas situações. Os regimes de responsabilidade civil existentes seriam suficientemente maleáveis para lidar com os novos conflitos frutos da relação humano-IA? Ao mesmo tempo em que a tecnologia traz inquestionáveis benefícios, ela vem acompanhada de diversos questionamentos que se mostram bastante presentes na seara jurídica. Falar em IA é mais do que falar em automação e numa possível perda de empregos: é também falar de danos e, sobretudo, de quem responderá por eles e a qual título.

Contudo, essa tarefa nem sempre é simples, em razão da falta de amostras adequadas e dados confiáveis sobre os efeitos e interações das novas tecnologias a longo prazo na sociedade, nos mais variados ambientes e entre diversos sujeitos. A principal razão para isso é que nem sempre se tem dados, experiência e imaginação suficientes para prever quais impactos negativos podem ser associados a um determinado robô ou IA, o que prejudica, em parte, eventuais intervenções em termos normativos e regulatórios. ${ }^{5}$ De todo modo, entende-se que as aplicações das normas jurídicas deverão se dar em diálogo com os debates mais recentes e de caráter multissetorial que estejam ocorrendo sobre o assunto e demais temas correlatos, como proteção de dados e cibersegurança.

No âmbito do Direito, parece adequada uma atuação tanto preventiva, buscando-se evitar ou minorar a ocorrência de danos, quanto a posteriori, isto é, quando o dano já foi causado e é preciso indenizar a vítima. Para isso, é necessário avaliar os deveres dos agentes envolvidos no desenvolvimento e aplicação da IA, bem como o regime e a estrutura de responsabilidade civil adequados nos casos de danos oriundos da IA. Exemplo desse trabalho pode ser realizado na hipótese de uma IA influenciar a tomada de decisões por parte de administradores de sociedades empresárias, as quais poderão impactar profundamente a estrutura da empresa, seus funcionários e seu valor no mercado.

explainable, fair, secure and with lineage, meaning that anyone could see very simply see how any application of AI developed and why."

5 "Não seria possível lidar com tantas e tão velozes inovações com base exclusivamente em regras codificadas ou estabelecidas em leis especiais. Isto porque a técnica regulamentar, por mais detalhada que seja, mostra-se insuficiente para solucionar problemas que, a cada dia, desafiam a imaginação do legislador e do magistrado. Daí a importância das cláusulas gerais e dos princípios que, de modo mais abrangente, permitem ao intérprete estabelecer padrões de comportamento coerentes com a tábua de valores do ordenamento. Esse processo de unificação do sistema jurídico só é possível mediante a aplicação direta das normas constitucionais. Somente estas, por sua posição hierarquicamente superior a todas as demais leis, conseguem exercer o papel de centralidade para a harmonização das fontes normativas, oferecendo segurança jurídica e preservando a unidade sistemática que caracteriza a própria noção de ordenamento." (TEPEDINO, 2019) 
Antes de se adentrar nesse debate, cabe ressaltar que a possibilidade de responsabilização, de um lado, poderá incentivar o desenvolvimento de bens e tecnologias mais seguros, claros e eficientes, mas, de outro, poderá acabar impactando negativamente as taxas de desenvolvimento de inovação e a adoção de novos negócios e tecnologias (SCHELLEKENS, 2015, p. 506-517), o que seria nocivo para a sociedade de forma geral. Há, portanto, um delicado e importante equilíbrio de interesses a ser atingido.

Entende-se que uma abordagem jurídica pessimista para a evolução tecnológica pode prejudicar o desenvolvimento de novos instrumentos que, efetivamente, venham a atuar no sentido de melhorar a qualidade de vida da população e trazer decisões empresariais mais eficientes e de risco controlado. Adicionalmente, não é demais lembrar que a melhor estrutura de regulação para a IA não deverá contemplar apenas o Direito, devendo ser também inseridos nesse esquema o mercado, as normas sociais e a arquitetura (LESSIG, 1999, p. 501549).

A atuação desses quatro elementos, operando de forma conjunta e relacionada, servirá tanto para incentivar quanto desestimular comportamentos de sujeitos e organizações, moldando estruturas e regulando situações. Nesse âmbito, princípios éticos, padrões técnicos e normas de estrutura menos fechada ajudarão a garantir que o desenho e o desenvolvimento de tais tecnologias sejam orientados pela preocupação com a pessoa humana e busquem promover uma IA segura, justa e inclusiva.

John McCarthy, conhecido como pai do termo Inteligência Artificial, assim a define: "a ciência e a engenharia de criar máquinas inteligentes, especialmente programas de computador inteligentes. Ela está relacionada à tarefa similar de utilizar computadores para entender a inteligência humana, mas a IA não tem que se confinar aos métodos que são biologicamente observáveis" (MCCARTHY, 2007)6. Já numa definição mais atual, de Jacob Turner (2019, p. 16), a inteligência artificial é compreendida como a habilidade de um ente não natural de fazer escolhas a partir de um processo de avaliação. ${ }^{7}$

As duas definições, contudo, não esgotam a amplitude da IA. Basta pensar que os carros autônomos, que pareciam ser uma imensa novidade, hoje já estão sendo considerados em certa medida uma tecnologia menos atual. Em alguns lugares se fala até em aviões sem pilotos comandados por IA. Mas se engana

${ }^{6}$ No original: "It is the science and engineering of making intelligent machines, especially intelligent computer programs. It is related to the similar task of using computers to understand human intelligence, but AI does not have to confine itself to methods that are biologically observable."

${ }^{7}$ A Inteligência Artificial tem por características principais: "i) o ímpeto de se auto aperfeiçoar; ii) o desejo de ser racional; iii) a busca pela preservação da utilidade de suas funções; iv) a prevenção da falsificação de seus resultados operacionais ou das suas propriedades funcionais; v) o desejo de adquirir recursos e usá-los de forma eficiente." (PIRES; SILVA, 2017, p. 244) 
quem pensa que os danos causados pela IA podem impactar apenas sistemas e robôs (SANTINO, 2019): já se tem notícia, por exemplo, de acidentes em fábricas e ruas que foram fatais para vítimas humanas (BELLONI, 2015) (TRINDADE, 2019) (SATURNO, 2018).

O que fazer nesses casos? Quem será responsável pelos danos causados se os resultados das ações da máquina não eram passíveis de previsão nem mesmo por aqueles que a desenvolveram? Qual será o regime de responsabilidade civil a ser adotado: o subjetivo ou objetivo? Com base em qual norma jurídica? Aplicando-se a teoria do risco, qual modalidade se encaixaria melhor: o risco criado, proveito ${ }^{8}$, profissional ou integral? Seria a teoria do risco do desenvolvimento aplicável aqui? Há muitas perguntas e, por enquanto, poucas respostas e certezas.

Fala-se, por exemplo, na atribuição de responsabilidade a diversos sujeitos (BONNET, 2015, p. 36-38; VLADECK, 2014, p. 127), tais quais: i) o titular de direitos de propriedade intelectual sobre a IA; ii) o produtor de um objeto dirigido por IA ou o projetista da IA; iii) o fornecedor, o vendedor ou o intermediário da IA; iv) o explorador da IA; v) o proprietário de um aparelho regido por IA; vi) o usuário da IA; vii) o treinador da máquina comandada por IA; e viii) os próprios robôs (SOUZA, 2017, p. 1475-1503). Diante da complexidade dos sistemas e das situações fáticas, num primeiro momento, não parece haver uma solução geral, mas sim, casuística, a depender, por exemplo, dos agentes envolvidos e de seus respectivos deveres, bem como do tipo e do grau de autonomia da IA envolvida. ${ }^{9}$

$\mathrm{O}$ aumento da capacidade de processamento da inteligência artificial, os avanços em algoritmos e a maior disponibilidade de dados representam fatores essenciais para o desenvolvimento de ponto importante para a maior aplicação

8 “(...) a conclusão mais razoável parece ser a de que a cláusula geral de responsabilidade objetiva dirige-se simplesmente às atividades perigosas, ou seja, às atividades que apresentam grau de risco elevado seja porque se centram sobre bens intrinsecamente danosos (como material radioativo, explosivos, armas de fogo etc.) seja porque empregam métodos de alto potencial lesivo (como o controle de recursos hídricos, manipulação de energia nuclear etc.) Irrelevante, para a incidência do dispositivo, que a atividade de risco se organize ou não sob forma empresarial ou que se tenha revertido em proveito de qualquer espécie para o responsável." (SCHREIBER, 2015, p. 25)

9 "Além do questionamento sobre a quem imputar a responsabilidade, costuma-se também levantar a importância do estabelecimento de uma espécie de seguro obrigatório para os fabricantes e usuários de determinadas tecnologias. No início de 2017, diante da complexidade de se atribuir responsabilidade pelos danos causados por robôs, o Parlamento Europeu adotou Resolução em que sugeriu o estabelecimento de um regime de seguros obrigatórios, conforme já acontece, por exemplo, com os carros tradicionais. No entanto, o mencionado seguro não deveria cobrir apenas os danos decorrentes de atos e falhas humanas. Um regime para a robótica teria que considerar todos os elementos potenciais da cadeia de responsabilidade. À semelhança do que acontece com os veículos motorizados, esse regime de seguros poderia ser complementado por um fundo de garantia de reparação de danos nos casos não abrangidos por qualquer seguro" (TEFFÉ, 2017). 
dessa tecnologia, qual seja, a velocidade para a tomada de decisões de qualidade. Afirma-se que, "Quanto mais avançadas e acessíveis se tornam as tecnologias de processamento e de armazenamento de dados, mais poderosos ficam os sistemas de Inteligência Artificial, simplesmente porque eles conseguem tomar decisões mais complexas em tempo hábil" (BIGONHA, 2018, p. 02). Nesse cenário, se os algoritmos representam o motor, por certo os dados são o combustível dessa revolução ${ }^{10}$, tendo em vista o crescente volume de informações produzidas e disponíveis, as quais apresentam diversidade em termos de natureza, forma de captação e possibilidade de tratamento, insumos esses de relevância elevada para as técnicas de aprendizado de máquina.

Hoje se busca por meio de tais técnicas que a tecnologia seja autossuficiente e possa analisar uma dada situação de múltiplas perspectivas, com o máximo de dados, para tomar a melhor decisão estatisticamente comprovada. Assim, computadores e dispositivos conectados podem desempenhar suas funções sem que pareçam programados, bem como aprender durante o processo de uso, utilizando o máximo de informações que conseguirem captar e gerar.

A partir do aprendizado de máquina ${ }^{11}$, muitas inteligências artificiais são capazes de se autoalimentar, criando novos padrões, o que se torna especialmente preocupante quando se percebe que, "com a habilidade de treinar a si mesma e acumular experiências, a IA pode tomar decisões independentemente da vontade de seu desenvolvedor e, inclusive, chegar a resultados sequer passíveis de previsão pelos seus programadores" (PIRES, 2017, p. 243). Essa imprevisibilidade é, sem dúvida, um dos atributos da IA que mais demanda atenção.

Diversos países já contam com planos e/ou regulações no campo da IA (LAWGORITHM, 2019). Destacam-se, dentre outros, China com o "Next Generation Artificial Intelligence Development Plan"; Índia (NATIONAL

10 "There is a saying in Silicon Valley that "Big Data is the new oil." What do people mean by this? Big Data is crucial to the use and development of algorithms and artificial intelligence ("AI"). Algorithms and AI are the machines; Big Data is the fuel that makes the machines run. Just as oil made machines and factories run in the Industrial Age, Big Data makes the relevant machines run in the Algorithmic Society." Numa tradução livre: Há um ditado no Vale do Silício de que "Big Data é o novo petróleo". O que as pessoas querem dizer com isso? O Big Data é crucial para o uso e o desenvolvimento de algoritmos e da inteligência artificial ("IA"). Algoritmos e IA são as máquinas; Big Data é o combustível que faz as máquinas funcionarem. Assim como o óleo fez as máquinas e fábricas funcionarem na Era Industrial, o Big Data faz com que as máquinas relevantes funcionem na Sociedade Algorítmica (BALKIN, 2018, p. 1154).

${ }^{11}$ A técnica do machine learning ou aprendizagem de máquina "faz com que a máquina aprenda certas funções a ponto de conseguir agir sem a interferência humana." (NUNES, Ana Carolina de Assis. Entre redes neurais naturais e artificiais: estudo antropológico sobre humanidade e inteligência artificial em algumas revistas brasileiras. Dissertação de Mestrado. Universidade Federal de Goiás, Faculdade de Ciências Sociais, Programa de Pós-Graduação em Antropologia Social. Goiânia, 2018, p. 49) 
STRATEGY FOR ARTIFICIAL INTELLIGENCE, 2018); Estados Unidos (EXECUTIVE ORDER ON MAINTAINING AMERICAN LEADERSHIP IN ARTIFICIAL INTELLIGENCE, 2019) (THE NATIONAL ARTIFICIAL INTELLIGENCE RESEARCH AND DEVELOPMENT STRATEGIC PLAN, 2016) ${ }^{12}$; e Canadá (CIFAR PAN-CANADIAN ARTIFICIAL INTELLIGENCE STRATEGY, 2019). A Europa, por sua vez, conta também com estratégia para a Inteligência Artificial, adotada em abril de 2018, além de um plano coordenado elaborado com os Estados-Membros para promover o desenvolvimento e a utilização dessa tecnologia. Vale lembrar que, em fevereiro de 2020, a Comissão europeia publicou o "Livro Branco sobre a inteligência artificial", em que afirma a necessidade de se reforçar a confiança na aplicação dessa tecnologia e traçar toda a política europeia com base nos valores e direitos fundamentais, como a dignidade humana e a proteção da privacidade.

Diante desse cenário, diversos pesquisadores vêm afirmando que o Brasil deveria desenvolver estratégias para o tema, a partir do reconhecimento de sua importância, construindo uma política nacional própria para essa área. No início de 2019, o Ministério da Ciência, Tecnologia, Inovações e Comunicações começou a ampliar projetos sobre IA e o Brasil, em maio do mesmo ano, aderiu aos princípios da OCDE (Organização para a Cooperação e Desenvolvimento Econômico) para a administração responsável de inteligência artificial. Esse teria sido o primeiro documento transnacional a incluir diretrizes para que os governos adotem sistemas de IA que respeitem os direitos humanos e valores democráticos. Os cinco princípios afirmam de forma resumida que:

1. AI should benefit people and the planet by driving inclusive growth, sustainable development and well-being. 2. AI systems should be designed in a way that respects the rule of law, human rights, democratic values and diversity, and they should include appropriate safeguards - for example, enabling human intervention where necessary - to ensure a fair and just society. 3 . There should be transparency and responsible disclosure around AI systems to ensure that people understand when they are engaging with them and can challenge outcomes. 4. AI systems must function in a robust, secure and safe way throughout their lifetimes, and potential risks should be continually assessed and

${ }^{12}$ Em janeiro de 2020, o Office of Science and Technology Policy, da Casa Branca, divulgou um memorando com 10 princípios para as agências governamentais aderirem ao propor regulamentos de Inteligência Artificial para o setor privado. A medida faz parte da American AI Initiative, ordem executiva assinada em fevereiro de 2019 pelo presidente Trump que implementa uma estratégia governamental, em colaboração com a iniciativa privada e a academia, para promover e proteger a tecnologia de IA dos Estados Unidos. (GUIDANCE FOR REGULATION OF ARTIFICIAL INTELLIGENCE APPLICATIONS, 2020) 
managed. 5. Organisations and individuals developing, deploying or operating AI systems should be held accountable for their proper functioning in line with the above principles. (OCDE, 2019)

Em diálogo com os princípios acima, em dezembro de 2019, o Ministério da Ciência, Tecnologia, Inovações e Comunicações lançou consulta pública para a futura Estratégia Brasileira de Inteligência Artificial (PARTICIPA BR, 2019). O objetivo é receber diversas contribuições para potencializar os benefícios da IA no Brasil e resolver problemas concretos. O documento propõe seis eixos verticais (educação e capacitação; força de trabalho; pesquisa, desenvolvimento, inovação e empreendedorismo; aplicação pelo governo; aplicação nos setores produtivos; e segurança pública) e três eixos transversais (legislação, regulação e uso ético; aspectos internacionais; e governança de IA).

Aponta Ronaldo Lemos que a IA deve ser vista como parte da infraestrutura de qualquer país, diante de sua capacidade de gerar externalidades positivas para as diversas atividades produtivas, tornando-as mais competitivas $\mathrm{e}$ eficientes. Recorda também a relevância dessa tecnologia para a segurança nacional: "países que não dominam inteligência artificial ficam cada vez mais para trás no terreno geopolítico" (LEMOS, 2019).

É possível, assim, afirmar que a ainda ausência de orientações mais objetivas e estruturadas sobre o tema leva a dúvidas acerca da legislação aplicável aos danos causados pelas inteligências artificiais, bem como em relação à possibilidade ou não do desenvolvimento de certos tipos de tecnologias, cabendo à doutrina e à jurisprudência a indicação de caminhos para se discutir os danos causados pela IA e a responsabilidade civil decorrente.

Vale lembrar que esses danos podem ocorrer nas mais diversas áreas. Desde o chatbot, que diz a uma criança que ela seria um demônio e que ele mataria toda a sua família (LARA, 2018), até o carro autônomo que, efetivamente, já matou mais de uma pessoa. Isso tudo sem mencionar, ainda, o papel de bots na disseminação de notícias falsas durante períodos eleitorais visando desinformar os cidadãos.

Mais especificamente na seara empresarial, os danos podem ser de diversas naturezas, como se abordará de forma mais detida no próximo capítulo. Nesse sentido, pode-se falar tanto em danos causados a terceiros quanto à própria sociedade empresária. Desde smart contracts até algoritmos enviesados e preconceituosos na seleção de um currículo ou na tomada de uma decisão importante. E se os seres humanos já enfrentam dificuldades em monitorar e aplicar determinadas inteligências artificiais, o que se dirá do futuro onde milhões ou mais coexistirão juntas (MOKHTARIAN, 2018)?

\section{APLICAÇÃO DA INTELIGÊNCIA ARTIFICIAL EM DECISÕES EMPRESARIAIS}

1. O uso de algoritmos e big data na tomada de decisões 
Administrar ou gerenciar uma sociedade empresária envolve a tomada constante de decisões importantes. Decisões essas que podem comprometer todo um orçamento, prejudicar o bem-estar dos funcionários e ter impactos imensuráveis. Uma escolha ruim pode levar uma companhia à falência ou obrigála a cortar bruscamente gastos. Por isso, racionalizar os sistemas decisórios representa uma tarefa cada vez mais relevante. Sem dúvida, uma importante aliada para essa atividade é a Inteligência Artificial ${ }^{13}$ que, através de seus algoritmos ${ }^{14}$ e do input de dados fornecidos, será capaz de apresentar possíveis respostas, além de propor estratégias matematicamente mais vantajosas para os problemas em pauta. A promessa é ousada: acredita-se que a máquina pode falhar menos do que o ser humano.

Ao tratar da utilização de algoritmos para fins de melhorar o processo decisório, Ana Frazão afirma que:

A exploração de algoritmos para tais fins encontra-se no contexto de um mercado multibilionário, cuja proposta é a de substituir as decisões humanas, consideradas naturalmente falhas $\mathrm{e}$ enviesadas, pelas escolhas algorítmicas, vistas como mais eficientes, objetivas e imparciais. Grandes empresas investem fortemente nesse segmento, não somente para ajudar clientes e consumidores - aí incluindo o próprio governo - em suas escolhas, como também para orientar seus próprios processos decisórios internos. (FRAZÃO, 2018)

$\mathrm{O}$ argumento central em defesa do uso da inteligência artificial é de que a máquina faria escolhas mais eficientes, objetivas e imparciais, ao passo que as decisões humanas tenderiam ao enviesamento e estariam mais sujeitas a falhas.

Ocorre que é preciso recordar que todo algoritmo precisa de um input inicial para funcionar. Em outros termos, isso significa que "a matéria-prima utilizada pelos algoritmos para tais decisões é o big data, ou seja, a enorme quantidade de dados disponíveis no mundo virtual que, com o devido processamento, pode ser

\footnotetext{
13 "Algorithms give computers guidance on how to solve problems. There is no artificial intelligence without algorithms. 'Algorithms are, in part, our opinions embedded in code.' They are 'often elegant and incredibly useful tools used to accomplish tasks". Numa tradução livre: Algoritmos fornecem aos computadores orientações sobre como resolver problemas. Não há inteligência artificial sem algoritmos. Algoritmos são, em parte, nossas opiniões incorporadas ao código. Eles são, muitas vezes, ferramentas elegantes e incrivelmente úteis usadas para realizar tarefas (MCKENZIE, 2018, p. 532-533)

${ }^{14} \mathrm{Um}$ algoritmo pode ser definido como um conjunto de regras que definem uma sequência de operações. Conjuntos de algoritmos podem ser usados para diversos fins, como o desenvolvimento de modelos de previsão de cenários e comportamentos. $\mathrm{Ou}$, ainda, um conjunto de instruções matemáticas ou regras que, especialmente se dadas a um computador, ajudarão a calcular uma resposta para um problema.
} 
transformada em informações economicamente úteis" (FRAZÃO, 2018), elas, por sua vez, "servirão como diretrizes e critérios para o processo decisório algorítmico" (FRAZÃO, 2018).

E este input que forma o big data é, pelo menos no início, dado pelo ser humano. Assim, de nada adianta criar um algoritmo pretensamente neutro, se o banco de dados que o alimenta já nasce enviesado. ${ }^{15,16}$ Basta pensar no recurso do Google Fotos que identificou pessoas negras como sendo gorilas (HARADA, 2015). Ou mesmo no caso da IA da Microsoft, Tay, que em apenas algumas horas após estrear no Twitter emitiu declarações racistas, antissemitas, sexistas, conspiratórias e revisionistas, as quais poderiam até mesmo ser qualificadas penalmente como injúrias raciais, crimes de incitação ao ódio e discriminação racial. ${ }^{17}$

A gravidade dessa utilização de dados pode ser bem compreendida na obra Automating Inequality: How high-tech tools profile, police, and punish the poor, na qual Virginia Eubanks lança luzes sobre a transformação ocorrida nas principais

15 “(...) na medida em que são elaborados por homens, é inequívoco que a racionalidade limitada dos programadores pode transpor para as fórmulas dos algoritmos uma série de vieses e problemas cognitivos, os quais, diante da falta de transparência, não terão como ser objeto do devido escrutínio social, da crítica e do aprimoramento. A falta de transparência é ainda mais reforçada quando se sabe que tais algoritmos são aperfeiçoados a partir da inteligência artificial, por meio da qual, com a aprendizagem automática e com as redes neurais artificiais, mais e mais algoritmos se desenvolvem independentemente, aprimorando a si mesmos e aprendendo com os próprios erros" (FRAZÃO, 2017a)

16 “(...) grande parte da literatura tem demonstrado o risco de discriminação inerente aos processos de tomada de decisão baseados em algoritmos, a qual ocorre, muitas vezes, de forma involuntária e sem o conhecimento dos tomadores de decisão (BAROCAS, 2015, p. 03). As razões pelas quais os algoritmos podem produzir resultados discriminatórios e prejudicar determinadas pessoas ou grupos sociais dividem-se em dois grandes grupos. Primeiramente, qualquer algoritmo só é tão bom quanto os dados que lhe servem como base (BAROCAS, 2015, p. 01). Isto é: a qualidade da decisão automatizada ("output"), baseada em um algoritmo, tem uma correlação direta com a qualidade dos dados que ele processa ("input"). Por isso, se o algoritmo se baseia em dados históricos repletos de preconceitos, ele reproduzirá, de forma automatizada, os mesmos padrões preconceituosos utilizados como base de seu processamento. Assim, é fácil perceber que, se forem utilizados no modelo estatístico dados com alto potencial discriminatório, tais como dados raciais, étnicos ou de orientação sexual, haverá um grande risco de que a decisão que resultará do processo automatizado (output) também seja discriminatória. (...) Em segundo lugar, é preciso observar que o próprio método utilizado nas decisões automatizadas - por meio da classificação e seleção dos indivíduos - gera um risco de se produzirem resultados discriminatórios, ainda que de forma não intencional." (DONEDA et al., 2018, p. 05)

${ }^{17}$ Em fevereiro de 2017, a Microsoft lançou Tay, sua inteligência artificial criada para interagir com os internautas de maneira totalmente autônoma. Somente algumas horas após sua estreia no Twitter, Tay emitiu declarações racistas, antissemitas, sexistas, conspiratórias e revisionista. Aqui, quem seria responsável pelo erro inumano de Tay (algoritmo de inteligência artificial): o designer, o usuário, o proprietário ou o chatbot? (SOULEZ, 2018, p. 83). 
decisões que determinam a vida das pessoas: desde a seleção de currículos para uma vaga de emprego, chegando até os seguros, acesso ao crédito e a serviços do governo. Decisões que, até pouco tempo, eram tomadas exclusivamente por seres humanos acabaram sendo delegadas no todo ou em parte para sistemas automatizados de elegibilidade, algoritmos de ranking e modelos de risco preditivo, que acabam controlando desde a concessão de crédito a uma pessoa até quem tem mais chances de delinquir, com base na análise computadorizada de estatísticas (DONEDA et al., 2018, p. 04). ${ }^{18}$

Percebe-se, assim, o potencial das decisões automatizadas de violarem direitos fundamentais, se tomadas sem o cumprimento de determinados parâmetros éticos e constitucionais que garantam sua transparência, possibilidade de controle, a participação do indivíduo no âmbito do processo decisório e a correção dos dados que serviam como input do algoritmo.

Nesse contexto, alude-se ao tratamento conferido ao tema pela Lei Geral de Proteção de Dados (LGPD, Lei n. 13.709/2018) que, na tentativa de conciliar a garantia do segredo industrial e empresarial, previu o direito de o titular dos dados solicitar a revisão de decisões tomadas ${ }^{19}$ unicamente com base em

18 "As decisões automatizadas, referentes a um indivíduo determinado, que se baseiam em um método estatístico para análise de grande volume de dados e informações, podem ter grande impacto sobre os direitos individuais, especialmente no que se refere à autonomia, igualdade e personalidade. Afinal, na sociedade atual, caracterizada pelas relações remotas, os dados pessoais acabam por se constituir na única forma de representação das pessoas perante as mais diversas organizações estatais e privadas, sendo determinantes para "abrir ou fechar as portas de oportunidades e acessos" (LYON, 2003, p. 27). Dessa forma, uma eventual representação equivocada em determinados contextos sociais - por meio de um equívoco do algoritmo ou dos dados em que o algoritmo se baseou - afetaria tanto a forma como o indivíduo se percebe como também o modo como a sociedade o enxerga e o avalia, afetando a sua integridade moral e a sua personalidade (BRITZ, 2008, p. 179). Ademais, se essa representação, conforme alertado por Lyon (2003), acarretar a perda de chances e oportunidades do indivíduo na sociedade, dar-se-á uma restrição indevida à sua autonomia, limitando a sua liberdade de ação, suas escolhas econômicas e até mesmo existenciais. Por fim, destaca-se também a possibilidade de violação do princípio da igualdade, na hipótese de que a classificação e seleção operada por algoritmos produza resultados desiguais para pessoas em situações semelhantes, afetando negativamente as suas oportunidades de vida na sociedade (LYON, 2003, p. 27).

${ }^{19}$ A sanção presidencial da Lei oㅜ 13.853, de 8 de julho de 2019, parece ter derrubado a revisão das decisões automatizadas por pessoas naturais, assunto esse que causou controvérsia durante a tramitação da MP 869/2018. Segundo especialista, "esse é um veto que não leva em conta o risco e a importância da decisão para o cidadão. Mas havia muita pressão das associações que representam as empresas na área de TI para que a revisão pelo usuário fosse retirada. $\mathrm{O}$ veto consta das sugestões enviadas à Casa Civil pela Brasscom, Associação Brasileira das Empresas de Tecnologia da Informação e Comunicação. A entidade entende que a obrigatoriedade da revisão humana de decisões automatizadas tem "impacto perverso no desenvolvimento de startups e novos empreendedores no país, impactando também a adoção de ferramentas de Inteligência Artificial e Big Data essenciais para o sucesso da Transformação Digital da economia brasileira". 
tratamento automatizado de dados pessoais que afetem seus interesses, incluídas as decisões destinadas a definir o seu perfil pessoal, profissional, de consumo e de crédito ou os aspectos de sua personalidade. Segundo parte da doutrina, o artigo 20 da LGDP seria em certa medida a sede do "direito à explicação"20, o qual derivaria do princípio internacionalmente reconhecido da transparência para o tratamento de dados pessoais ${ }^{21}$.

Vale recordar que essa disposição na LGPD dialoga com o regulamento europeu de proteção de dados (General Data Protection Regulation - GDPR) que, em seu considerando 71, afirma que o titular dos dados deverá ter o direito de não ficar sujeito a uma decisão que avalie aspectos pessoais que lhe digam respeito, que se baseie exclusivamente em tratamento automatizado e que produza efeitos jurídicos que lhe digam respeito ou o afetem significativamente de modo similar, como a recusa automática de um pedido de crédito, por via eletrônica, ou práticas de recrutamento eletrônico sem qualquer intervenção humana.

O mencionado tratamento inclui a definição de perfis mediante qualquer forma de tratamento automatizado de dados pessoais para avaliar aspectos pessoais relativos a uma pessoa natural, em especial a análise e previsão de aspetos relacionados com o desempenho profissional, a situação econômica, saúde, preferências ou interesses pessoais, fiabilidade ou comportamento, localização ou deslocações do titular dos dados, quando produza efeitos jurídicos que lhe digam respeito ou a afetem significativamente de forma similar.

Afirma-se que tal tratamento deverá ser acompanhado de garantias adequadas, que deverão incluir informação específica ao titular dos dados e o

Em um momento em que o mundo todo debate o uso ético da Inteligência Artificial, e formas de tentar minimizar os vieses da tecnologia, deixar aos cuidados de outro algoritmo a revisão de uma decisão automatizada é um contrassenso, para dizer o mínimo. Já hoje não faltam casos nos quais as decisões automatizadas orientadas por modelos com viés, intencionais ou não, alimentados por dados incompletos, imprecisos ou tendenciosos, podem levar a estigmatização, à discriminação e à consolidação de preconceitos. O PLC aprovado em abril de 2019 transferia para a ANPD a responsabilidade de regulamentar os casos em que a revisão por pessoa natural. Um ponto considerado positivo, na época, mas que acabou criando outros problemas, na opinião do professor Danilo Doneda. O texto abria margem à interpretação de que a revisão por humanos só seria possível depois de regulamentada pela ANPD. O que nos deixaria dependentes de uma regulamentação, sem que a lei deixasse claro os critérios para esta regulamentação. Ainda assim, isso era melhor do que não poder ter humanos auditando algoritmos. A grande questão é que hoje os algoritmos da maioria das gigantes digitais e das empresas que já utilizam sistemas de Inteligência Artificial são considerados segredos industriais. Seria preciso haver um equilíbrio entre os direitos dos cidadãos e a preservação dos segredos industriais (DE LUCA, 2019)

20 Debate-se, aqui, se deveria haver uma obrigatoriedade da revisão humana de decisões automatizadas. Sobre o assunto, conferir: Monteiro (2018) e Frazão (2019).

${ }^{21}$ Segundo o art. 5ํ, VI, da LGPD, o princípio da transparência representa "garantia, aos titulares, de informações claras, precisas e facilmente acessíveis sobre a realização do tratamento e os respectivos agentes de tratamento, observados os segredos comercial e industrial". 
direito de obter a intervenção humana, de manifestar o seu ponto de vista, de obter uma explicação sobre a decisão tomada na sequência dessa avaliação e de contestar a decisão. Destaca-se que essa medida não deverá dizer respeito a uma criança, cuidado esse não disposto na lei brasileira.

Por fim, o Considerando 71 do GDPR dispõe que:

A fim de assegurar um tratamento equitativo e transparente no que diz respeito ao titular dos dados, tendo em conta a especificidade das circunstâncias e do contexto em que os dados pessoais são tratados, o responsável pelo tratamento deverá utilizar procedimentos matemáticos e estatísticos adequados à definição de perfis, aplicar medidas técnicas e organizativas que garantam designadamente que os fatores que introduzem imprecisões nos dados pessoais são corrigidos e que o risco de erros é minimizado, e proteger os dados pessoais de modo a que sejam tidos em conta os potenciais riscos para os interesses e direitos do titular dos dados e de forma a prevenir, por exemplo, efeitos discriminatórios contra pessoas singulares em razão da sua origem racial ou étnica, opinião política, religião ou convicções, filiação sindical, estado genético ou de saúde ou orientação sexual, ou a impedir que as medidas venham a ter tais efeitos. A decisão e definição de perfis automatizada baseada em categorias especiais de dados pessoais só deverá ser permitida em condições específicas.

Esse panorama permite concluir, parcialmente, que tão ou mais importante que o algoritmo é a base de dados a ele subjacente e o enviesamento que pode vir a reboque, o que realça ainda mais a necessidade de se efetivar a cartela de direitos e princípios fundamentais estabelecidos aos titulares dos dados na LGPD.

\section{Exemplos da aplicação de inteligência artificial na tomada de decisões empresariais}

Fundadas as premissas iniciais de que a adoção da IA vem agasalhar uma necessidade crescente de maior objetividade e eficiência decisória, bem como apontada a importância da base de dados que alimenta os algoritmos, cabe agora analisar possíveis exemplos da aplicação de inteligência artificial na tomada de decisões empresariais.

Para fins meramente didáticos, pode-se dividir a aplicação da IA no âmbito empresarial em duas grandes áreas: a utilização externa e a utilização interna. Isto é, pode-se utilizar a IA para fazer a interface com terceiros, a exemplo de robôs 
que atendem chamadas telefônicas ou chatbots em aplicativos e sites ${ }^{22}$, como também para processos decisórios internos. A presente análise abordará com mais detalhe a última possibilidade.

Assim, é possível se pensar na utilização da IA em diferentes áreas de uma empresa: desde o marketing, havendo a análise de padrões de comportamentos para a realização de campanhas publicitárias (ZANATTA, 2019), até a opção de decidir com quem contratar ou como e onde investir, isto é, algoritmos que dizem, com base em dados, qual a melhor parceira para fazer negócios ou quais negócios valem o risco.

Especialistas sobre o tema elencaram as principais aplicações, a saber: (i) melhoria na infraestrutura, soluções e serviços; (ii) aperfeiçoamento dos sistemas de defesa em cibersegurança; (iii) maiores benefícios em cuidados de saúde das pessoas; (iv) automação no processo de recrutamento de novos empregados; (v) interfaces de conversação inteligentes; (vi) redução no uso de energia e de custos; (vii) previsão de exploração de vulnerabilidades; (viii) melhoria na análise das respostas de consumidores a pesquisas de satisfação; (ix) previsão de mercado; (x) aceleração do processo de leitura, em comparação com seres humanos; (xi) melhoria na contabilidade e análise financeira; (xii) melhoria nas regras de cobrança dos consumidores; (xiii) melhor compreensão de intenções e comportamentos; e (xiv) revisão de propostas.

Como se vê, há variadas aplicações destinadas a elevar a eficiência na realização de atividades na e para a empresa, atividades essas que a força de trabalho humana poderia levar mais tempo para realizar ou para as quais seria necessário destacar um número mais alto de funcionários, por exemplo.

Diante desse panorama, é possível afirmar que os agentes empresariais podem ser, por vezes, em alguma medida, responsabilizados pela escolha do sistema operado pela Inteligência Artificial, pelo conjunto de informações e aplicações que fornecem ao banco de dados que alimentará o algoritmo e pela adoção de caminhos propostos pela IA de forma acrítica ou sem uma base maior de dados.

Ademais, é possível pensar numa responsabilização pela confiança depositada ou não depositada na escolha indicada pelo algoritmo. Explica-se: é possível ocorrer um dano não só em razão de o agente tomar uma decisão com base no caminho indicado pelo algoritmo, mas também por negligenciá-lo e atuar contrariamente a ele. Imagine-se, nesse sentido, que a companhia tenha deliberado que as decisões acerca da inabilitação de sociedades para se fazer negócios deva passar pela chancela de um algoritmo responsável por ranquear as sociedades e indicar quais não seriam boas - a partir de critérios previamente definidos - para realizar negociações. Assim, caso uma empresa fosse classificada como inadequada ou ruim e o agente empresarial contrariasse tal parecer e

${ }^{22}$ Um exemplo a ser conhecido é o da Amazon Robotics que utiliza robôs para a interface com o público de consumidores. 
optasse por realizar o negócio, poder-se-ia pensar numa responsabilização pela sua conduta. ${ }^{23}$

Fala-se hoje, até mesmo, numa aplicação perversa da inteligência artificial para a prática de condutas anticoncorrenciais. ${ }^{24} \mathrm{~A}$ ideia é que a prática delitiva, que antes era realizada fisicamente por seres humanos, seja transferida para as máquinas, que passam a estabelecer a partir de análises comparativas e negociações o ajuste de preços:

Computadores sofisticados são centrais para a competitividade dos mercados atuais e futuros. Com o desenvolvimento acelerado da IA, eles estão prontos para mudar o cenário competitivo e a natureza das restrições competitivas. À medida que os mecanismos de precificação mudam para os algoritmos de precificação de computadores, o mesmo também ocorrerá com os tipos de colusão. Estamos mudando de um mundo em que os executivos expressamente praticam a colusão em quartos de hotel cheios de fumaça para um mundo onde os algoritmos de precificação continuamente monitoram e se ajustam aos preços e dados de mercado um do outro. (EZRACHI; STUCKE, 2017, p. 1775 , tradução livre) $)^{25}$

23 "Uma nota explicativa do Secretariado da UNCITRAl, acerca da Convenção das Nações Unidas sobre Utilização de Comunicações Eletrônicas em Contratos Internacionais, estabelece, no seu artigo 12, o princípio de que a pessoa, natural ou jurídica, em cujo nome um computador foi programado, deve ser responsável por qualquer mensagem gerada pela máquina. Ou seja, a máquina que negocia vincula o seu proprietário ou a pessoa em nome de quem ela agiu. (...) Ou seja, a disposição garante que uma negociação eletrônica travada por uma IA seja considerada perfeita, reconhecendo como válida a manifestação de vontade por si exarada, bem como as obrigações daí decorrentes, sem reconhecer, contudo, a personalidade jurídica da IA, atribuindo a responsabilidade pelos seus atos à pessoa em cujo nome a IA agiu. Essa interpretação está em conformidade com a regra geral de que o operador de uma ferramenta é responsável pelos resultados obtidos pelo seu uso, uma vez que a ferramenta não tem volição independente própria" (PIRES; SILVA, 2017, p. 247-248).

24 "Imagine-se o caso de um cartel implementado pelos algoritmos utilizados pelos diversos agentes econômicos de determinado mercado. Seria razoável considerar pelo menos culposa a conduta do agente que se utiliza, voluntariamente e sem os cuidados devidos, de mecanismos de tomada de decisão (como a precificação) que podem levar a práticas concertadas ou outros tipos de ilícito antitruste." (FRAZÃO, 2018)

${ }^{25}$ No original: Sophisticated computers are central to the competitiveness of present and future markets. With the accelerating development of $\mathrm{AI}$, they are set to change the competitive landscape and the nature of competitive restraints. As pricing mechanisms shift to computer pricing algorithms, so too will the types of collusion. We are shifting from the world where executives expressly collude in smoke-filled hotel rooms to a world where pricing algorithms continually monitor and adjust to each other's prices and market data. 
Isso evidencia o que se tem denominado por mathwashing, que pode ser definido como: "a suposição de que modelos algorítmicos não possuem subjetividade incorporada a eles porque eles envolvem matemática $(\mathrm{JOH}, 2017$, p. 292 , tradução livre $)^{26}$. Ou seja, os agentes se esconderiam por trás da aparente neutralidade dos processos decisórios algorítmicos, reforçando mais uma vez a ideia de que a matemática suprimiria a subjetividade inerente às decisões humanas.

Um exemplo bastante claro já foi apontado pela doutrina estrangeira: a seleção de novos empregados. A seguinte passagem é esclarecedora no que tange ao mecanismo de operação com IA:

A definição de um funcionário desejável é desafiadora porque requer a priorização de numerosas características observáveis que tornam um empregado "bom". Empregadores tendem a valorizar empregados orientados para a ação, inteligentes, produtivos, detalhistas. Essa decisão subjetiva abre as portas para problemas potenciais. Essencialmente, o que faz um "bom" empregado "deve ser definido de maneiras que correspondam a resultados mensuráveis: vendas relativamente mais altas, produção em mais curto tempo ou maior continuidade, por exemplo. "No entanto, escolhas subjetivas feitas tanto pelos programadores quanto pelo empregador em decisões de contratação anteriores são absorvidas pelo algoritmo com base nos dados que são usados e os rótulos subjetivos são colocados em características específicas. Assim, quando rótulos subjetivos são aplicados, os resultados inclinam-se ao longo das linhas desses rótulos e dos dados que são utilizados. Portanto, é possível que algoritmos e a inteligência artificial herdem preconceitos anteriores e reflitam preconceitos atuais. (MCKENZIE, 2018, p. 534) $)^{27}$

\footnotetext{
${ }^{26}$ No original: the assumption that algorithmic models don't have subjectivity baked into them because they involve math.

27 No original: The definition of a desirable employee is challenging because it requires prioritization of numerous observable characteristics that make an employee "good." Employers tend to value action-oriented, intelligent, productive, detailoriented employees. This subjective decision opens the door to potential problems. Essentially, what makes a "good" employee "must be defined in ways that correspond to measurable outcomes: relatively higher sales, shorter production time, or longer tenure, for example." However, the subjective choices made both by the programmers and by the employer in previous hiring decisions are absorbed into the algorithm by way of the data that is used and the subjective labels placed on specific characteristics. Thus, when subjective labels are applied, the results are skewed along the lines of those labels and the data that is utilized. Therefore, it is possible for algorithms and artificial intelligence to inherit prior prejudice and reflect current prejudices.
} 
A última frase do trecho acima vem ao encontro do que se tem defendido: os algoritmos podem herdar preconceitos, o que afasta a pretensa neutralidade que se atribui a eles, reforçando que tão ou mais importante que os algoritmos são os dados que os alimentam. E tais dados, geralmente, vêm de agentes, funcionários e prepostos empresariais, os quais podem ser responsabilizados também pela "má alimentação" aos algoritmos.

Resta ainda saber a extensão da delegação decisória para os algoritmos, isto é, pode o agente delegar completamente uma ação à máquina ou esta só deve fornecer elementos para análise consultiva do agente?

Em suma, pode-se dizer que a responsabilidade dos agentes empresariais reside, por exemplo, no grau de confiança que eles depositam no algoritmo comandado por inteligência artificial, nos dados que eles fornecem para alimentar as máquinas e, ainda, na obediência ou não aos comandos do algoritmo para a tomada de decisões.

\subsection{Caminhos dentro da responsabilidade civil}

Quando sistemas e robôs comandados por inteligência artificial tomam decisões e, em razão delas, causam danos a terceiros, evidencia-se a necessidade de se analisar qual sistema de responsabilidade civil deverá ser aplicado, bem como de se determinar o responsável pela reparação. Diante disso, na seara da responsabilidade civil, é possível pensar em alguns caminhos.

Inicialmente, pode-se cogitar da aplicação de um regime de responsabilidade semelhante àquele estabelecido pelo fato da coisa ou pelo risco (na forma do parágrafo único do art. 927 do Código Civil) ${ }^{28}$. No primeiro caso, o esquema seria próximo ao aplicável para os animais ${ }^{29}$ : seu dono ou detentor ressarcirá o dano por ele causado, a menos que prove culpa da vítima ou força maior. O art. 936, ao

28 Assim esclarecem Tepedino e Silva (2019, p. 293-320): “(...) o reconhecimento da configuração de atividades de risco a partir do emprego generalizado de sistemas de inteligência artificial parece a solução adequada, em linha de princípio, para o equacionamento da questão atinente à individualização do critério de imputação do regime de responsabilidade. O que não parece possível, ao revés, é a invocação indiscriminada e irrefletida da noção de atividade de risco. Devese, com efeito, lançar mão dos critérios desenvolvidos pela doutrina para a elucidação do que vem a ser atividade de risco para fins de incidência da correlata cláusula geral de responsabilidade objetiva. Há que se investigar detidamente, em cada atividade, à luz das especificidades dos respectivos sistemas e de seu contexto, a possibilidade de caracterização de atividade de risco".

${ }^{29}$ ČERKA et al. (2015, p. 386) são contrários à equiparação de sistemas inteligentes a animais, diante da falta de bases similares para aproximá-los, já que as atividades de uma IA são baseadas num processo algorítmico que se avizinha mais do processo racional humano do que dos instintos e sentidos dos animais. Assim, presume-se que uma IA possa vir, de certo modo, a compreender as consequências de suas ações, o que seria uma marca distintiva para o caso dos animais, levando a uma impossibilidade de se adotar um regime de responsabilidade civil objetiva, nos moldes da teoria da guarda de um animal. 
trazer apenas duas excludentes do dever de indenizar, introduz claramente hipótese de responsabilidade civil objetiva. ${ }^{30}$ Aqui, "a responsabilidade distanciase, de certa forma, do campo da guarda, em sua acepção clássica, e vai encontrar seu fundamento contemporâneo na teoria do risco, no sentido de que quem tem o uso do animal suporta o risco pelos danos que eventualmente venha a provocar" (TEPEDINO; BARBOZA; BODIN DE MORAES, 2012, p. 846)

Dessa forma, o responsável pela IA teria que lidar com o risco decorrente da imprevisibilidade da atuação dela. No campo da responsabilidade civil objetiva, poder-se-ia pensar também na sua forma agravada para situações específicas. Em um cenário de riscos maiores, Fernando Noronha (2003) entende que seria dispensável até mesmo o nexo de causalidade, desde que o risco fosse inerente à atividade geradora do dano. Para o autor, existiriam hipóteses especiais em que seria possível prescindir também de nexo de causalidade para se passar a exigir unicamente que o dano pudesse ser considerado risco inerente à própria atividade em causa, risco característico ou típico dela. ${ }^{31}$

Além disso, vale lembrar que, quando se tratar de relação de consumo, o Código de Defesa do Consumidor e sua consequente responsabilidade civil objetiva deverão ser aplicados para os casos em que o dano causado pela Inteligência Artificial puder ser enquadrado como vício ou fato do produto ou do serviço (VLADECK, 2014, p. 128-129). Alguns defendem até que deveria ser adotada como premissa a presunção de que qualquer dano causado pela IA seria necessariamente resultado de uma falha humana res ipsa loquitur ${ }^{32}$, fosse ela uma falha de projeto, de fabricação, de montagem ou de informação acerca da segurança e do uso apropriado do produto (PIRES, 2017, p. 250).

30 Sobre o artigo em questão, recorda-se o enunciado 452 do Conselho da Justiça Federal: "A responsabilidade civil do dono ou detentor de animal é objetiva, admitindo-se a excludente do fato exclusivo de terceiro."

31 "A responsabilidade objetiva agravada insere-se no final de uma evolução que começou quando, num primeiro momento, se reconheceu que o requisito culpa não sempre era imprescindível para o surgimento da obrigação de indenizar: o exercício de determinadas atividades, suscetíveis de causar danos a terceiros, implicava, em contrapartida aos benefícios que elas proporcionavam ao agente, o ônus de suportar os danos que eventualmente fossem causados a outrem. Foi por isso que se construiu a teoria da responsabilidade objetiva. Agora estamos entrando num segundo momento, em que se verifica haver hipóteses especiais em que se prescinde também de nexo de causalidade, para se passar a exigir unicamente que o dano acontecido possa ser considerado risco próprio da atividade em causa" (NORONHA, 1999, p. 37)

32 Segundo dicionário jurídico norte-americano, a expressão latina pode ser definida como "the thing speaks for itself". Afirma-se que: "In tort law, a principle that allows plaintiffs to meet their burden of proof with what is, in effect, circumstantial evidence. The plaintiff can create a rebuttable presumption of negligence by the defendant by proving that the harm would not ordinarily have occurred without negligence, that the object that caused the harm was under the defendant's control, and that there are no other plausible explanations". Disponível em: $<$ https://www.law.cornell.edu/wex/res_ipsa_loquitur> Acesso em: 27.06.19. 
É o que defende David Vladeck (2014, p. 128-129) 33, que formula uma solução, na linha da teoria do fato do produto, "por meio da presunção de existência de um defeito na IA, comprovada pela própria ocorrência do dano. Isto é, conclui-se que tanto a IA era defeituosa que o dano ocorreu" (MULHOLLAND, 2019, p. 341). Com isso, "o fornecedor da IA - no caso, o agente que explora a tecnologia seria obrigado a reparar o dano, pois estaria na melhor posição para arcar com as perdas, fundamentando-se esse argumento no princípio da solidariedade social e do risco da atividade" (MULHOLLAND, 2019, p. 341).

Nessa ordem de ideias, Tepedino e Silva entendem tornar-se "induvidosa a possibilidade de responsabilização de todos os fornecedores integrantes da cadeia de consumo pelos danos decorrentes de fato do produto ou serviço resguardada, em qualquer caso, a necessidade de aferição dos demais elementos relevantes para a deflagração do dever de indenizar" (TEPEDINO; SILVA, 2019, p. 293-320).

Há também autores que sugerem a aplicação da teoria do deep pocket que, em linhas gerais, prescreve que os agentes por trás de atividades consideradas perigosas deveriam compensar os danos causados à sociedade a partir dos lucros obtidos. Dessa maneira, o agente, seja ele qual for, que tiver o "bolso profundo", isto é, quem tiver a melhor capacidade para gerir os riscos dessas atividades perigosas deverá atuar como uma espécie de garantidor delas, o que se operaria preferencialmente por meio de um seguro obrigatório de responsabilidade civil (ČERKA; GRIGIENE்; SIRBIKYTE், 2015, p. 386).

Importa registrar, ainda, que parte da doutrina discute se a crescente autonomia dos robôs e sistemas comandados por Inteligência Artificial deveria apartar a discussão da responsabilidade da lógica do defeito do produto/serviço. Haveria, pois, dois planos distintos.

Num primeiro, seria possível vislumbrar os danos causados por robôs autônomos que resultem de defeitos. Isso permitiria enquadrá-los como produtos que possam ter falhas de concepção, fabricação, informação (do fornecedor ao usuário final) ou de desenvolvimento. Nesse caso, seriam aplicadas as normas

33 "Of course, the solution suggested by existing law would be to hold the vehicle's manufacturer liable and let the manufacturer seek indemnity or contribution from other potentially responsible parties, if any. But that approach may be nothing more than an empty gesture. If it is in fact impossible to identify the cause of the accident, then the manufacturer would likely have no reasonable grounds for an indemnity or contribution action, and would thus be saddled with the entire judgment. That result might make sense if the manufacturer is in the best position to bear the loss. Otherwise, it might be fairer to apportion responsibility among all of the parties that participated in building and maintaining the vehicle's autonomous systems, on the ground that the cost of error is better spread among all potentially responsible parties or among the parties who could more efficiently guard or insure against the loss. The other approach would be to hold the vehicle itself responsible, assuming, of course, that the law is willing to confer legal 'personhood' on the vehicle and require the vehicle to obtain adequate insurance". 
consumeristas relativas ao fato do produto ou do serviço, sem prejuízo da aplicação de outras normas (CAMPOS, 2019, p. 712).

Num segundo plano, os danos não adviriam "de um defeito do robô, mas antes da autonomia que revela, ou seja, reconduz-se a uma ideia de 'não é defeito, é feitio'"(CAMPOS, 2019, p. 712). Daí a afirmação de que "os robôs com uma capacidade profunda de autoaprendizagem são imprevisíveis, pelo que uma resposta inesperada para uma situação específica pode não ser o resultado de uma falha do produtor" (CAMPOS, 2019, p. 712).

Nesse sentido, recorda-se questionamento apontado pela doutrina:

A tomada de decisão da AI, a partir do self-learning poderia ser equiparado a um defeito de concepção imputável ao fornecedor? O defeito de concepção é caracterizado pelo erro de projeto ou pela escolha equivocada dos materiais a serem utilizados na fabricação do produto, de tal maneira que a insegurança está diretamente ligada, como o próprio termo explicita, à concepção ou idealização. Seria esse o caso da tomada de decisão da AI ou estar-se-ia tratando apenas de um desdobramento independente e autônomo a partir da nova realidade tecnológica? (MAGRANI; SILVA; VIOLA, 2019, p. 133-134)

Diante dessa realidade, autores como Ugo Pagallo chegam a defender a necessidade de serem estabelecidos novos mecanismos para a responsabilidade civil:

Contrary to the traditional viewpoint of robots as mere tools of the principal, so that humans should automatically be bound by all the operations of the artificial agent, new liability policies have to be taken into account. Indeed, a number of cases have shown that third parties, rather than individuals bearing responsibility for the care of their agents, are in the best position to prevent harm or damages and, thus, such third parties are the least-cost avoider of the risk. (PAGALLO, 2013, p. 212)

Essa discussão abre espaço, ainda, para questionamentos mais profundos, como saber se as máquinas devem ou não ser concebidas como sujeitos de direito autônomos com direitos e deveres próprios (PAGALLO, 2013, p. 169).

Discute-se, ainda, a possibilidade de adoção da teoria do risco do desenvolvimento ${ }^{34}$ para os casos de danos causados pela IA $^{35}$. Verifica-se que ela

34 "Ao contrário do que ocorre em outros países, nossa lei consumerista não menciona os riscos de desenvolvimento, que são aqueles riscos que, imperceptíveis devido ao estado da ciência no 
eventualmente poderá ser arguida para se tentar afastar a responsabilidade do fabricante ou proprietário de robôs e demais tecnologias dotadas de inteligência artificial. O risco do desenvolvimento tem como objetivo tratar daqueles riscos não cognoscíveis pelo mais avançado estado da ciência e da técnica no momento da introdução do produto ou serviço no mercado e que só vêm a ser descobertos após um período de uso do mesmo, seja em razão de acidentes e danos, seja por avanços nos estudos e testes realizados. Em razão da condição narrada, há quem entenda que, nessa hipótese, a responsabilidade do fornecedor deveria ser excluída. Isso ocorreria não porque o fornecedor falhou em seus deveres de diligência e segurança, mas sim porque a incognoscibilidade do defeito era absoluta diante do presente estado da arte (TEFFÉ, 2017).

Nesse raciocínio, não haveria subversão de uma legítima expectativa de segurança do consumidor, visto que nenhuma expectativa poderia ser tida como legítima se pretende ir além do próprio estado mais avançado da tecnologia de sua época. Por outro lado, há quem entenda que sua aplicação poderia acabar permitindo que o consumidor arcasse sozinho com a incerteza da tecnologia adquirida. Além de não ter pleno conhecimento dos riscos e do grau de conhecimento alcançado pela Ciência, ele ainda assumiria integralmente os danos que viesse a sofrer decorrentes do uso normal do produto ou serviço (TEFFÉ, 2017).

Acerca dessa questão, já se manifestou Mulholland:

as mesmas críticas feitas à adoção da teoria do risco de desenvolvimento como fator de atribuição da obrigação de reparar o dano causado por um produto podem ser aplicadas ao

momento em que o produto ou serviço é colocado no mercado, vêm posteriormente a se revelar com o desenvolvimento do conhecimento técnico e científico" (SCHREIBER, 2018, p. 659).

35 Esclarece Mulholland (2019, p. 335) que "Nesse caso, a teoria do risco de desenvolvimento poderia ser resgatada como forma de embasar a atribuição de responsabilidade aos agentes empresariais que desenvolvem ou exploram a IA, justificando-a no princípio da solidariedade social. Seus elementos podem ajudar a criar uma teoria a ser aplicada a estes casos. São elementos do risco de desenvolvimento (i) o dano causado por um produto - que não é, em tese, defeituoso; (ii) a impossibilidade técnica objetiva de reconhecimento, tanto por parte do fornecedor quanto do consumidor, da defeituosidade e da potencialidade danosa do produto, no tempo da ocasião do dano; e (iii) o desenvolvimento tecnológico que identifica, posteriormente, um defeito do produto, gerador do dano. Esses requisitos, se aplicados às hipóteses de danos causados por IA autônoma, poderiam ser igualmente interpretados para fins de atribuição da obrigação de indenizar. Senão vejamos: (i) o dano é casualmente ligado a um sistema de IA; (ii) é virtualmente impossível identificar, no momento inicial de programação da IA, a previsibilidade e potencialidade danosa da aplicação do sistema; e (iii) o desenvolvimento da aprendizagem autônoma pela IA, que independe de interferência humana, causa efetivamente o dano a uma pessoa. A estes três elementos, soma-se um quarto que é (iv) a inviabilidade de explicação por um humano do processo que levou a IA a uma decisão autônoma geradora do resultado danoso, na medida em que esses processos de aprendizagem e decisão independem atuação e da racionalidade humana". 
reconhecimento da responsabilidade civil pelos danos ocasionados pela tomada de decisão autônomas por sistemas de IA, sendo o principal questionamento aquele que diz respeito ao delicado equilíbrio entre a atribuição de responsabilidade por meio de medidas regulatórias e o consequente e eventual risco de estagnação da inovação tecnológica. É possível que a adoção da teoria do risco de desenvolvimento nessas hipóteses gere um retrocesso em termos de desenvolvimento tecnológico, pois a gestão dos riscos não justificaria o investimento em sistemas totalmente autônomos. (MULHOLLAND, 2019)

Em âmbito empresarial, em havendo transferência de capacidade decisória para algoritmos, sem os devidos cuidados, mostra-se possível trabalhar com estruturas de responsabilização, em casos de danos aos mais diversos sujeitos, como, por exemplo, a própria pessoa jurídica, os sócios, os empregados, os credores, os consumidores ou terceiros. Os entes coletivos têm o dever de se organizar corretamente (TIEDEMANN, 1988; FRAZÃO, 2017b, p. 23-57), podendo ser especificamente responsabilizados quando deixarem de empregar meios de controle e precaução capazes de garantir que suas atividades sejam desenvolvidas de maneira lícita e que os riscos assumidos sejam ponderados e monitorados. Cobra-se, assim, atitude corporativa que adote todas as medidas organizativas razoáveis e indispensáveis para impedir delitos. A realidade multifacetada das relações e tomadas de decisões em uma corporação exige, portanto, a adoção de modelos organizativos.

No que concerne ao administrador de sociedade, recorda-se da responsabilidade subjetiva por violação ao dever de diligência (CARVALHOSA; LATORRACA, 1997; LAMY FILHO; PEDREIRA, 2017). Conforme dispõe o art. 153 da lei das Sociedades por Ações (Lei n. 6.404/1976), o administrador tem obrigação de atuar com cuidado, atenção e zelo. No mesmo sentido, o artigo 1.011 do Código Civil afirma que o administrador da sociedade deverá ter, no exercício de suas funções, o cuidado e a diligência que todo homem ativo e probo costuma empregar na administração de seus próprios negócios.

Por sua posição, o administrador exerce competências funcionais, não podendo agir em proveito próprio. Os poderes de gestão que são conferidos a ele são para o atendimento exclusivo dos interesses da pessoa jurídica, sendo vedado agir em favor de si mesmo ou de terceiros.

Para a doutrina, o administrador considerado diligente é aquele que emprega na condução dos negócios cautelas, métodos e recomendações próprios da ciência da administração. $\mathrm{O}$ dever de diligência relaciona-se, por isso, diretamente com os deveres de atuar em boa-fé e de informação. Busca-se, desse modo, impedir que os administradores coloquem na frente seus interesses pessoais em detrimento 
daqueles da sociedade ou que sejam negligentes ou imprudentes na administração da companhia.

Nesse sentido, um administrador diligente é entendido como íntegro, honesto e justo. Ao exercer suas funções, ele desempenha as atividades no interesse da companhia e de forma atuante, ágil e participativa, mas necessariamente também cuidadosa, cautelosa e com a presteza esperada de um administrador em posição e circunstâncias similares.

Com a inserção da Inteligência Artificial, a mencionada postura do administrador será essencial, pois, como aponta Frazão, "em qualquer circunstância de delegação de suas competências para sistemas de inteligência artificial, as decisões ou atos serão imputados ao administrador e o sujeitarão à responsabilidade pessoal" (FRAZÃO, 2019, p.495), já que foi ele quem encampou aquela decisão como se fosse sua.

O artigo 1.016 do Código Civil traz a cláusula geral de responsabilidade civil de administradores: "Os administradores respondem solidariamente perante a sociedade e os terceiros prejudicados, por culpa no desempenho de suas funções." Caminha, assim, ao encontro da norma prevista na lei das S.A. Nela, a regra é a de que o administrador não é pessoalmente responsável pelos atos que pratica no exercício regular de sua gestão, que são considerados como atos da sociedade e, portanto, a ela imputáveis. Todavia, ele responderá pessoalmente em dois casos: quando agir dentro de suas atribuições ou poderes, com culpa ou dolo, ou se agir com violação da lei ou do estatuto social. Entende-se que a disposição do artigo 158 é de ordem pública e tem como destinatária da tutela toda a sociedade e não apenas a companhia ou seus acionistas. O fim dessa responsabilidade é prevenir e obstar a ocorrência de atos ilícitos e reparar os prejudicados dos danos causados.

Uma vez que a responsabilidade civil dos administradores tem natureza subjetiva, afirma-se que a culpa deverá ser compreendida em seu sentido normativo e aferida à luz dos deveres de diligência e lealdade.

Anota-se que há atitudes que podem contribuir para uma atuação considerada diligente (BLANCHET; SILVA, 2014), as quais, por vezes, poderão servir como parâmetros para a análise de processos envolvendo a responsabilidade de administradores, a saber: a) tempo dedicado à função; b) tomada de decisões de maneira informada, refletida e desinteressada; c) participação ativa, analisando propostas, alternativas e riscos, a partir de seu alinhamento com a política e finalidade da companhia; d) compartilhamento de conhecimento e discussão com os demais administradores; e) assessorar-se com especialistas, principalmente quando as decisões dependerem ou envolverem especialidade, ponto esse através do qual a IA pode penetrar tanto para melhor informar e especializar o administrador quanto para propor estratégias e caminhos, devendo, porém, tal utilização da IA ser feita com a diligência esperada de um administrador, o qual deve se assegurar de que, de fato, ela tem qualificação necessária para desempenhar, total ou parcialmente, as tarefas a ela delegadas; f) delegação de 
tarefas com responsabilidade e supervisão; e) utilização de seu direito de confiar nos outros de forma limitada e cautelosa, situação essa em que também é possível se pensar na aplicação da IA, quando, por exemplo, o administrador optar por seguir determinado caminho ou proposta sugerido pela tecnologia, devendo, para tanto, agir com prudência e cuidado na escolha da IA, em seu treinamento e na adoção de suas propostas, principalmente quando envolverem decisões determinantes para a companhia; e f) atuação conforme o que é razoavelmente esperado de uma pessoa em posição e situação similares.

Nesse sentido, acerca da responsabilidade civil em âmbito empresarial por uso de Inteligência Artificial e algoritmos para a tomada de decisões, ensina Frazão que:

(...) é possível falar em ato ilícito, ainda que não doloso, quando a empresa (i) adota algoritmo sem saber como ele age - violação ao dever de diligência por tomar decisão não informada -; ou (ii) não toma as providências necessárias para, a partir do monitoramento dos resultados práticos da utilização dos algoritmos, evitar a colusão ou outros tipos de conduta anticoncorrencial - violação ao dever de diligência por ausência de controle de risco. Nesse caso, seria possível se cogitar da responsabilidade tanto da pessoa jurídica, como dos gestores. Na verdade, o próprio defeito de organização pode ser visto como uma violação ao dever de diligência, pois já se viu que, no atual contexto, este último ganha uma dimensão organizativa, relacionada ao compromisso de criar e manter organização eficiente e idônea para o controle do risco assumido. Logo, a violação do referido dever tanto poderá ensejar a responsabilidade civil, como também a responsabilidade no âmbito do direito punitivo. (FRAZÃO, 2018)

Em suma, responde o administrador tanto pela escolha quanto pelo monitoramento da IA. ${ }^{36}$ Contudo, sendo o dever de diligência um dever de meio, uma vez cumprido adequadamente, a responsabilidade do administrador não será deflagrada mesmo se o sistema de IA aplicado causar danos. O dever de diligência não impõe que o administrador tome sempre a decisão mais acertada para o sucesso econômico da pessoa jurídica. Busca-se, aqui, cuidado com o processo decisório e com os recursos utilizados para tanto. É essencial que os

36 “(...) não se pode afastar a responsabilidade pessoal dos administradores de sociedades empresárias por danos decorrentes de sistemas de inteligência artificial em razão da culpa in elegendo pela escolha da tecnologia. A partir do momento em que o administrador delega parte dos processos decisórios da sociedade empresária para um sistema de inteligência artificial, o mínimo que se espera é que tenha agido com prudência e cautela na escolha desse sistema" (FRAZÃO, 2019, p. 506). 
administradores possam assumir determinados riscos com alguma tranquilidade, sob pena de sua atuação restar indevidamente engessada e de faltarem pessoas interessadas em ocupar tal posição, em razão do regime de responsabilidade imposto.

Ressalta-se, por fim, a necessidade de o administrador e demais agentes envolvidos nas decisões empresariais demandarem por mais transparência algorítmica, com o devido cuidado, claro, para que essa transparência respeite o sigilo que deve haver nos negócios. Além disso, recomenda-se também o desenvolvimento de estruturas éticas corporativas para que as empresas aumentem os benefícios da IA e minimizem seus riscos e problemas. Como destaca doutrina:

O desenvolvimento de uma estrutura ética corporativa ajuda as empresas a demonstrar como os dados que lhes são confiados são usados de maneira responsável. A ética é também uma ferramenta flexível, permitindo que as empresas alinhem e atualizem, continuamente, as práticas no ritmo do desenvolvimento tecnológico, abordando questões que vão além da estrita conformidade legal. O recurso à ética como quadro analítico e operacional reconhece que a legislação não cobre tudo (nem deveria), e que os quadros éticos corporativos podem desempenhar um papel importante na avaliação e decisão sobre o uso de dados e processos algorítmicos (...) a ética justifica e facilita o desdobramento de um conjunto de práticas corporativas adicionais que não derivam de obrigações ou exigências legais, permitindo que as empresas sigam os valores que definiram e cumpram a sua missão integralmente. Tais práticas corporativas podem incluir, entre outras, investimentos em programas sociais, compromisso com iniciativas de transparência e apoio a campanhas educacionais. A ética também pode ajudar as empresas a atender às expectativas e a seguir as recomendações dos órgãos reguladores, contribuindo para um relacionamento mais saudável e produtivo com essas entidades. (DONEDA et al., 2018, p. 14)

Ao implantar sistemas algorítmicos, mostra-se essencial conhecer suas limitações e o que é efetivamente levado em conta para a tomada de decisões. Entender os limites dos algoritmos ajudará o agente a melhor julgar suas decisões e propostas, evitando, assim, visões simplistas e reducionistas, sob pena de tornar as pessoas, em certa medida, reféns de decisões tomadas na "caixa-preta" dos algoritmos, cuja opacidade é denunciada por Frank Pasquale em sua análise sobre os algoritmos secretos que acabam controlando o dinheiro e a informação na sociedade contemporânea (PASQUALE, 2015). 


\section{CONCLUSÃo}

Como visto, os danos causados pela Inteligência Artificial já são realidade. Não se trata mais de uma projeção futurista de obras de ficção científica. Ao contrário, são danos que já estão causando repercussões na sociedade e, também, batendo às portas do Judiciário, o que reforça a necessidade de o Direito se precaver para dar uma resposta que, ainda que não consiga resolver todos os problemas, possa, ao menos, encontrar caminhos para reduzir os impactos.

Diversas são as searas afetadas, o que impõe uma análise multissetorial do problema, levando-se em conta as principais forças de regulação: arquitetura, normas sociais, mercado e Direito. É preciso entender as peculiaridades que as diversas inteligências artificiais impõem para melhor adequar as normas de responsabilidade civil aos problemas atuais e regular os novos conflitos e questões.

Neste campo, mostra-se importante reavaliar os esquemas de imputação de responsabilidade e os regimes impostos às relações, de forma a tanto incentivar a inovação e a aplicação da IA - de maneira ética, segura e inclusiva - quanto promover a adequada reparação dos danos causados.

Para tanto, além de um elevado investimento em capacitação dos profissionais, são sugeridos como instrumentos o desenvolvimento de estruturas éticas corporativas e uma agenda brasileira para a aplicação da inteligência artificial, que leve em conta considerações de ordem ética e os princípios e direitos fundamentais.

Não será fácil compreender as repercussões oriundas da transferência - em alguma medida - de decisões para algoritmos na sociedade e nos ambientes empresariais. Entretanto, a interação entre humanos e inteligências artificiais, bem como sua elevada aplicação, já é uma realidade e será cada vez mais intensa. Uma abordagem pessimista ou pouco preparada para a evolução tecnológica pode prejudicar o desenvolvimento de instrumentos que efetivamente venham a atuar no sentido de melhorar a qualidade de vida da população, a eficiência no ambiente produtivo e a qualidade das decisões empresariais.

$\mathrm{O}$ presente estudo pretendeu, assim, instigar o debate na seara da responsabilidade civil dos agentes empresariais pelos danos causados pela utilização de sistemas dotados de Inteligência Artificial. Longe de esgotar a análise, objetivou-se demonstrar que é preciso atentar, sobretudo, para o grau de autonomia destinado a tais sistemas, de maneira a se evitar que a delegação decisória à máquina, aparentemente neutra, objetiva e impessoal, venha a esconder algum enviesamento ou deturpação de dados.

Como exposto, tão ou mais importantes que os algoritmos são os dados, os quais servem de combustível para essa revolução. A expansão da IA vem por vezes causando danos, os quais precisam de uma resposta do Direito que seja 
assertiva e proporcional, para se evitar um cenário de irresponsabilidade, mas, acima de tudo, para se permitir que a inovação aconteça. $\mathrm{O}$ novo pede passagem: cabe ao Direito acompanhá-lo.

\section{REFERÊNCIAS}

AFFONSO, Filipe José Medon. Inteligência artificial e danos: autonomia, riscos e solidariedade. 2019. Dissertação Mestrado em Direito - Faculdade de Direito, Universidade do Estado do Rio de Janeiro, Rio de Janeiro, 2019.

BALKIN, Jack M. Free Speech in the Algorithmic Society: Big Data, Private Governance, and New School Speech Regulation. Yale Law School: Faculty Scholarship Series, n. 5160, 2018. Disponível em $<$ https://digitalcommons.law.yale.edu/cgi/viewcontent.cgi?article=6159\&context=f ss_papers> Acesso em 02 mar. 2019.

BARBOSA, Mafalda Miranda. Inteligência Artificial, E-persons e Direito: desafios e perspectivas. Revista Jurídica Luso Brasileira, v. 3, n. 6, 2017, p. 1475-1503.

BELLONI, Luiza. Robô mata trabalhador dentro da fábrica da Volkswagen na Alemanha. Publicado em 02 de julho de 2015. Disponível em: $<$ https://www.huffpostbrasil.com/2015/07/02/robo-mata-trabalhador-dentro-dafabrica-da-volkswagen-na-alemanh_n_7714702.html> Acesso em: 20 abr. 20.

BIGONHA, Carolina. Inteligência Artificial em perspectiva. Panorama setorial da Internet. Inteligência Artificial e ética, a. 10, n. 2, out. 2018. Disponível em: $<$ https://www.cetic.br/publicacao/ano-x-n-2-inteligencia-artificial-e-etica/> Acesso em: 19 abr. 20.

BLANCHET, Richard; SILVA, Lucila. A responsabilidade dos administradores e o dever de diligência. GT Interagentes, 2014. Disponível em:

<http://www.ibgc.org.br/userfiles/files/GT_Interagentes_Responsabilidade_Admi nistradores.pdf> Acesso em: 02 mar. 19.

BONNET, Adrien. La Responsabilité du fait de l'intelligence artificielle. Banque de Memóires, Université Panthéon-Assas - Paris II, 2015.

CARVALHOSA, Modesto; LATORRACA, Nilton. Comentários à lei de sociedades anônimas. v. 3. São Paulo: Saraiva, 1997. 
CAMPOS, Juliana. A Responsabilidade Civil do produtor pelos danos causados por robôs inteligentes à luz do regime do Decreto-Lei n.o 383/89, de 6 de novembro. Revista de Direito da Responsabilidade, a. 1, 2019.

ČERKA, Paulius; GRIGIENĖ, Jurgita; SIRBIKYTĖ, Gintarè. Liability for damages caused by Artificial Intelligence. Computer Law \& Security Review, Elsevier, v. 31, n. 3, p. 376-389, 2015.

CIFAR PAN-CANADIAN ARTIFICIAL INTELLIGENCE STRATEGY, 2019. Disponível em: <https://www.cifar.ca/ai/pan-canadian-artificial-intelligencestrategy> Acesso em 20 jun. 2019.

COLEMAN, Lauren deLisa. CES 2019: Why IBM CEO Ginni Rometty's Opening Address Delivers. Disponível em:

$<$ https://www.forbes.com/sites/laurencoleman/2019/01/09/ces-2019-why-ibm-ceoginni-rommetys-opening-address-delivers/\#1460654720d5> Acesso em: 28 jun. 19.

DE LUCA, Cristina. Bolsonaro sanciona lei que cria a autoridade de dados pessoais com 14 vetos. Blog Porta 23. UOL. Publicado em 09 de julho de 2019. Disponível em: <https://porta23.blogosfera.uol.com.br/2019/07/09/bolsonarosanciona-lei-que-cria-a-autoridade-de-dados-pessoais-com-14vetos/?fbclid=IwAR0ihxRR9UQ5tPHHLFHnHkiGofqJcZWLTmL5mu3bEqD3K4O 7cgDMFC6-Cpk> Acesso em: 09.07.19.

DONEDA et al. Considerações iniciais sobre inteligência artificial, ética e autonomia pessoal. Pensar, Fortaleza, v. 23, n. 4, p. 1-17, 2018.

EXECUTIVE ORDER ON MAINTAINING AMERICAN LEADERSHIP IN ARTIFICIAL INTELLIGENCE. Publicado em 11 de fevereiro de 2019. Disponível em: $<$ https://www.whitehouse.gov/presidential-actions/executive-ordermaintaining-american-leadership-artificial-intelligence/> Acesso em: 28 jun. 19.

EZRACHI, Ariel; STUCKE, Maurice. Artificial Intelligence \& Collusion: When Computers Inhibit Competition. University of Illinois Law Review, v. 2017.

FRAZÃO, Ana. Algoritmos e inteligência artificial. Jota, publicado em 15 de maio de 2018. Disponível em: <https://www.jota.info/opiniao-eanalise/colunas/constituicao-empresa-e-mercado/algoritmos-e-inteligenciaartificial-15052018> Acesso em: 08 fev. 2019 
FRAZÃO, Ana. Dados, estatísticas e algoritmos. Jota, publicado em 28 de junho de 2017 (2017a). Disponível em: <https://www.jota.info/opiniao-eanalise/colunas/constituicao-empresa-e-mercado/dados-estatisticas-e-algoritmos28062017> Acesso em 19 fev. 2019

FRAZÃO, Ana. Programas de compliance e critérios de responsabilização de pessoas jurídicas por ilícitos administrativos. In: ROSSETTI, Maristela; PITTA, Andre (Coord.). Governança corporativa: avanços e retrocessos. São Paulo: Quartier Latin, 2017 (2017b).

FRAZÃO, Ana. Responsabilidade civil de administradores de sociedades empresárias por decisões tomadas com base em sistemas de inteligência artificial. In: FRAZÃO, Ana; MULHOLLAND, Caitlin (Coord.). Inteligência artificial e direito: ética, regulação e responsabilidade. Editora Revista dos Tribunais, 2019.

GUIDANCE FOR REGULATION OF ARTIFICIAL INTELLIGENCE APPLICATIONS, 2020. Disponível: <https://www.whitehouse.gov/wpcontent/uploads/2020/01/Draft-OMB-Memo-on-Regulation-of-AI-1-7-19.pdf> Acesso em: 23 jan. 20

HARADA, Eduardo. Fail épico: sistema do Google Fotos identifica pessoas negras como gorilas. Tecmundo, publicado em 01 de julho de 2015. Disponível em: $<$ https://www.tecmundo.com.br/google-fotos/82458-polemica-sistema-googlefotos-identifica-pessoas-negras-gorilas.htm> Acesso em 17 maio 2019.

JOH, Elizabeth E. Feeding the Machine: Policing, Crime Data, \& Algorithms. J. William \& Mary Bill of Rights Journal, v. 26, n. 2, 2017.

LAMY FILHO, Alfredo; PEDREIRA, José Luis Bulhões. Direito das Companhias. Rio de Janeiro: Forense, 2017.

LARA, Rodrigo. SimSimi: app de conversa com inteligência artificial é risco para crianças? UOL. Publicado em 24 de abril de 2018. Disponível em:

$<$ https://www.uol.com.br/tilt/noticias/redacao/2018/04/24/simsimi-app-deconversa-com-inteligencia-artificial-e-risco-para-criancas.htm> Acesso em: 20 abr. 20. 
LAWGORITHM. Estratégias nacionais de inteligência artificial. Publicado em: 12 de setembro de 2019. Disponível em: <https://lawgorithm.com.br/estrategiasia/> Acesso em: 20 abr. 20

LEMOS, Ronaldo. É preciso plano de inteligência artificial. Folha, publicado em: 04 fev. 2019. Disponível em:

$<$ https://www1.folha.uol.com.br/colunas/ronaldolemos/2019/02/e-preciso-planode-inteligencia-artificial.shtml>. Acesso em: 19 fev. 2019

LESSIG, Lawrence. The Law of the Horse: What Cyberlaw Might Teach. Harvard Law Review, v. 113, 1999, p. 501-549. Disponível em:

$<$ https://cyber.harvard.edu/works/lessig/finalhls.pdf> Acesso em: 13 out. 2018.

MCCARTHY, John. What is artificial intelligence? 2007. Disponível em:

$<$ http://www-formal.stanford.edu/jmc/whatisai/node1.html> Acesso em: 07 fev. 2019.

MAGRANI, Eduardo; SILVA, Priscilla; VIOLA, Rafael. Novas perspectivas sobre ética e responsabilidade de Inteligência Artificial. In: FRAZÃO, Ana;

MULHOLLAND, Caitlin (coords.). Inteligência Artificial e Direito: ética, regulação e responsabilidade. São Paulo: Thomson Reuters Brasil, 2019.

MCKENZIE, Raub. Bots, Bias and Big Data: Artificial Intelligence, Algorithmic Bias and Disparate Impact Liability in Hiring Practices. Arkansas Law Review, v. 71, n. 2, 2018.

MOKHTARIAN, Edmund. The Bot Legal Code: Developing a Legally Compliant Artificial Intelligence. VAND. J. ENT. \& TECH. L., v. 21, n. 1, 2018.

MONTEIRO, Renato Leite. Existe um direito à explicação na Lei Geral de Proteção de Dados do Brasil? Artigo estratégico 39. Dezembro de 2018.

MULHOLLAND, Caitlin. Responsabilidade civil e processos decisórios autônomos em sistemas de Inteligência Artificial (IA): autonomia, imputabilidade e responsabilidade. In: FRAZÃO, Ana; MULHOLLAND, Caitlin (Coord.). Inteligência artificial e direito: ética, regulação e responsabilidade. Editora Revista dos Tribunais, 2019. 
NATIONAL STRATEGY FOR ARTIFICIAL INTELLIGENCE. Índia, 2018. Disponível em: <http:/niti.gov.in/writereaddata/files/document_publication/ NationalStrategy-for-AI-Discussion-Paper.pdf> Acesso em 20 fev. 2019

NORONHA, Fernando. Direito das obrigações. v. 1. São Paulo: Saraiva, 2003.

NORONHA, Fernando. Desenvolvimentos contemporâneos da responsabilidade civil. Revista dos Tribunais, v. 761, 1999.

OCDE. Recommendation of the Council on Artificial Intelligence, 2019. Disponível em: <https://www.oecd.org/going-digital/forty-two-countries-adoptnew-oecd-principles-on-artificial-intelligence.htm> Acesso em: 28 jun. 19.

PAGALLO, Ugo. The Laws of Robots: Crimes, Contracts and Torts. Law, Governance and Technology Series, v. 10. Springer, 2013.

PARTICIPA BR. Consulta pública sobre a Estratégia Brasileira de Inteligência Artificial. 2019. Disponível em: <http://participa.br/estrategia-brasileira-deinteligencia-artificial/legislacao-regulacao-e-uso-etico> Acesso em: 18 dez. 2019.

PASQUALE, Frank. The Black Box Society. The Secret Algorithms That Control Money and Information. Cambridge: Harvard University Press, 2015.

PIRES, Thatiane Cristina Fontão; SILVA, Rafael Peteffi da. A responsabilidade civil pelos atos autônomos da inteligência artificial: notas iniciais sobre a resolução do Parlamento Europeu. Rev. Bras. Polít. Públicas, v. 7, n. 3, 2017.

ROBLES, Pablo. China plans to be a world leader in Artificial Intelligence by 2030. Publicado em 01 de outubro de 2018. Disponível em $<$ https://multimedia.scmp.com/news/china/article/2166148/china-2025-artificialintelligence/index.html> Acesso em 20 fev. 2019.

SANTINO, Renata. Robô-rebelde 'morre' após ser atropelado por carro autônomo. Olhar digital. Publicado em: 14 de janeiro de 2019. Disponível em: $<$ https://olhardigital.com.br/noticia/robo-rebelde-morre-apos-ser-atropelado-porcarro- autonomo/81217>. Acesso em 19 fev. 2019

SATURNO, Ares. Robô perfura spray acidentalmente e deixa 54 feridos em armazém da Amazon. Canaltech. Publicado em: 07 de dezembro de 2018. 
Disponível em: <https://canaltech.com.br/curiosidades/robo-perfura-sprayacidentalmente-e-deixa-54-feridos-em-armazem-da-amazon-128575/> Acesso em: 01 mar. 2019.

SCHELLEKENS, Maurice. Self-driving cars and the chilling effect of liability Law. Computer Law \& Security Review, v. 31, n. 4, 2015.

SCHREIBER, Anderson. Manual de Direito Civil Contemporâneo. São Paulo: Saraiva Educação, 2018.

SCHREIBER, Anderson. Novos Paradigmas da Responsabilidade Civil: Da Erosão dos Filtros de Reparação à Diluição dos Danos. 6. ed. São Paulo: Editora Atlas, 2015.

SOULEZ, Marie. Questions juridiques au sujet de l'intelligence artificielle. Enjeux numériques, n.1, março de 2018. Disponível em: <http://www.annales.org/enjeuxnumeriques/2018/resumes/mars/15-en-resum-FR-AN-mars-2018.html\#15FR> Acesso em 14 fev. 2019.

SOUZA, Carlos Affonso Pereira de. O debate sobre personalidade jurídica para robôs. Errar é humano, mas o que fazer quando também for robótico? Jota, publicado em 10 de outubro de 2017. Disponível em: $<$ https://www.jota.info/opiniao-e-analise/artigos/o-debate-sobre-personalidadejuridica-para-robos-10102017> Acesso em: 20 abr. 2018.

TEFFÉ, Chiara Spadaccini. Quem responde pelos danos causados pela IA? Jota, publicado em 24 de outubro de 2017. Disponível em: $<$ https://www.jota.info/opiniao-e-analise/artigos/quem-responde-pelos-danoscausados-pela-ia-24102017> Acesso em: 23 fev. 2019.

TEFFÉ, Chiara Spadaccini; MEDON, Filipe. A utilização de inteligência artificial em decisões empresariais: notas introdutórias acerca da responsabilidade civil dos administradores. In: FRAZÃO, Ana; MULHOLLAND, Caitlin (Coord.). Inteligência artificial e direito: ética, regulação e responsabilidade. Editora Revista dos Tribunais, 2019.

TEPEDINO, Gustavo; BARBOZA, Heloisa Helena; BODIN DE MORAES, Maria Celina. Código Civil Interpretado conforme a Constituição da República. v. 2. 2.ed. Renovar: Rio de Janeiro, 2012. 
TEPEDINO, Gustavo; SILVA, Rodrigo da Guia. Inteligência Artificial e elementos da responsabilidade civil. In: FRAZÃO, Ana; MULHOLLAND, Caitlin (Coord.). Inteligência artificial e direito: ética, regulação e responsabilidade. Editora Revista dos Tribunais, 2019.

TEPEDINO, Gustavo. As tecnologias e a renovação do Direito Civil. Publicado em 12 de junho de 2019. Disponível em: <http://www.oabrj.org.br/colunistas/gustavotepedino/as-tecnologias-renovacao-direito-civil?fbclid=IwAR1PumTlccleKgJQzAbrV6o1Odgqzh1CkrA_va5UsHbu3RWyYgTkrn2V9M> Acesso em: 28 jun. 19.

\section{THE NATIONAL ARTIFICIAL INTELLIGENCE RESEARCH AND} DEVELOPMENT STRATEGIC PLAN. Publicado em outubro de 2016. Disponível em: <https://www.nitrd.gov/news/national_ai_rd_strategic_plan.aspx> Acesso em 20 fev. 2019.

TIEDEMANN, Klaus. Punibilidad y Responsabilidad Administrativa de las Personas Jurídicas y de sus Órganos. Revista Jurídica de Buenos Aires, v. 2, 1988.

TRINDADE, Rodrigo. Como acidente fatal mudou o programa de carros autônomos da Uber. UOL. Publicado em 16 de novembro de 2019. Disponível em: $<$ https://www.uol.com.br/tilt/noticias/redacao/2019/11/16/como-acidente-fatalmudou-o-programa-de-carros-autonomos-da-uber.htm> Acesso em: 20 abr. 20.

TURNER, Jacob. Robot Rules. Regulating artificial intelligence. Palgrave Macmillan: Londres, 2019.

VLADECK, David C. Machines without principals: liability rules and artificial intelligence. Washington Law Review, v. 89, n. 117, 2014.

ZANATTA, Rafael A. F. Perfilização, Discriminação e Direitos: do Código de Defesa do Consumidor à Lei Geral de Proteção de Dados Pessoais. Publicado em: fevereiro de 2019. Disponível em: <https://www.researchgate.net/publication/ 331287708> Acesso em: 27 jun. 19. 